\title{
E MOZART? E O ASSASSINATO?
}

\section{Howard S. Becker}

\author{
Tradução de Guilherme Santana e Simone Rocha
}

Três campos que na superfície podem parecer ter muito pouco em comum - as sociologias do desvio, da arte e da ciência - possuem uma profunda similaridade subjacente, que emerge como uma luta crônica sobre definições. Investigar tais lutas e similaridades nos diz algo interessante. Começarei com dois exemplos da minha própria experiência como participante nessas discussões. ${ }^{1}$

Quando publiquei Outsiders, em 1963, morava em São Francisco, muito perto da Universidade da Califórnia, em Berkley, que possuía, entre seus vários anexos, o Centro para o Estudo do Direito e da Sociedade, então dirigido pelo merecidamente renomado intelectual Philip Selznick. Selznick acolheu em seu centro um grupo de estudantes do "desvio", estudo do que, variavelmente, havia sido denominado "desorganização social" ou, como vem sendo chamado, criminologia - Jerome Skolnick, David Matza, Sheldon Messinger, e outros -, em-

Artigo recebido em 20/03/2014

Aprovado em 08/04/2014 bora ele próprio tivesse sérias dúvidas acerca dessa temática. No curso natural dos acontecimentos, fui convidado a apresentar, no Centro, a teoria da "rotulação" aplicada ao desvio, cujo livro Outsiders serviu como um primeiro exemplo.

Recordo-me claramente daquela ocasião. Expus as ideias contidas no primeiro capítulo do livro - que o desvio não era uma qualidade inata ou natural do ato de alguém, mas, sim, o resultado da atividade conjunta de tal ator e das pessoas que responderam sobre sua atividade rotulando-a como "desviante". ${ }^{2}$ Isso contrariou a ideia comum de que essas categorias corresponderiam ao que as pessoas realmente eram, aos aspectos essenciais de suas personalidades, e, portanto, facilmente definíveis. Um criminoso cometeu crimes, uma pessoa anormal fez coisas que pessoas normais não faziam.

Quando terminei, houve o habitual momento para perguntas e discussão. Lembro-me de Phil Selznick, em pé na porta do fundo da sala, fumando um charuto, olhando-me com curiosidade e per- 
guntando-me de maneira delicada: "Bem, Howie, vejo aonde você quer chegar. É muito interessante". E depois, vindo para destruir: "Mas, afinal, e o assassinato? Isso não é realmente desviante?” Ele se recostou, convencido de que havia apresentado um argumento devastador. Eu não concordava e repliquei com contra-argumentos familiares: que pessoas sensatas diferiam sobre quais atos de morte eram assassinato e quais não eram; que essas diferenças variavam dependendo de quais tipos de pessoas estavam envolvidas; do momento histórico, e assim por diante. Ele não achou que eu tivesse respondido sua pergunta. Eu achei que sim.

Antes de analisar este exemplo, acrescentarei outro. Alguns anos depois, quando eu estava lecionando na Northwest Univesrsity, o então decano da Faculdade de Artes e Ciências, Rudolph Weingartner, inaugurou uma série de Palestras do Decano e pediu-me para ministrar uma sobre o tema de meu novo livro, Art words. Embora eu não tenha colocado desta maneira no livro, Art words apresentou o que poderia ser razoavelmente chamado de uma teoria da "rotulação" aplicada à arte, segundo a qual um dos componentes dessa abordagem geral sobre a arte consistia em considerá-la uma atividade coletiva, algo que as pessoas faziam conjuntamente. $\mathrm{O}$ componente da rotulação estava ligado ao problema de definir a arte como objeto de estudo, problema este que tinha deixado estetas perplexos por milênios e não mostrou sinais de solução. De forma um tanto arrogante, solucionei o problema ao recusar uma tentativa de definição, propondo como alternativa o estudo das ocasiōes em que as pessoas definiam coisas como arte e discutiam acerca de definiçôes.

À medida que eu apresentava essas ideias em minha palestra, o decano ficava cada vez mais visivelmente incomodado. Ele estava pronto para a primeira pergunta: "Bem, Howie, tudo isso é muito interessante, mas, afinal de contas, e Mozart?" Eu estava preparado para essa questão com uma resposta apropriada, embora vaga: "E Mozart?", retruquei. O decano olhou surpreso (ele pensou que o sentido da pergunta estava claro o bastante para uma pessoa sensata) e disse: "Bem, Mozart não é realmente um gênio musical?” E dei a resposta óbvia: se você aceitou todas as premissas de uma abordagem específica sobre arte, então certamente Mozart foi um gênio. Mas as pessoas frequentemente rejeitam essas premissas e, se assim o fazem, podem não concordar com essa conclusão. $\mathrm{O}$ decano, como Selznick, achou que tinha apresentado um argumento devastador e que eu não havia respondido de maneira aceitável. Achei novamente que minha resposta tinha sido bastante adequada.

Não consigo apresentar um exemplo proveniente da sociologia da ciência baseado em minha própria experiência de pesquisa, mas os exemplos podem ser encontrados em todos os lugares deste campo. A questão capital assume duas formas ligeiramente diferentes. A versão positiva é: "E os aviōes?" Se você responde, tal como fiz ao decano, a resposta é: "Bem, você não acredita na ciência quando esta diz que eles vão voar? Se não acredita, por que você sempre embarca em um?" Todas as pessoas envolvidas em tais argumentos são intelectuais contemporâneos que às vezes voam constantemente, então, trata-se de um sério desafio: por que eles fazem isso se suas próprias pesquisas e pensamentos indicam que a ciência é "simplesmente" uma questão de consenso?

A forma negativa da questão capital na sociologia da ciência é: "E a astrologia?" Se você diz "O que é que tem?", o próximo passo é perguntar se, assumindo que a ciência seja apenas consenso, você acha que antigamente a astrologia era verdade quando todos os sábios acreditavam nela? Sociólogos da ciência respondem que, sendo pessoas contemporâneas e sensatas, eles acreditam que os aviōes vão voar e não se preocupam em ler seu horóscopo no jornal. Mas eles acrescentam que, já que os cientistas muitas vezes acreditam de forma consensual em coisas que gerações posteriores de cientistas deixam de acreditar, eles também pensam ser provável que os cientistas, no futuro próximo, irão considerar muitas coisas que a ciência contemporânea trata como uma verdade óbvia da mesma forma como nós, hoje, pensamos a respeito da astrologia. E, mais uma vez, os críticos acreditam ter apresentado um argumento devastador, mas os sociólogos pensam que não.

Em todos os três casos, um campo de pesquisa empírica (uma ciência) substituiu um campo de discurso filosófico. ${ }^{3} \mathrm{O}$ que antes era o reino 
da argumentação baseado em exemplos canônicos e raciocínio lógico se tornou um empreendimento segundo o qual cientistas chegam a conclusóes com base na investigação sistemática do mundo real, desconfiando mais do que a discussão filosófica habitualmente o faz. Esse processo já aconteceu muitas vezes na história da filosofia. A física e outras ciências naturais já foram temas filosóficos, mas a discussão dos fenômenos físicos e biológicos há muito deu lugar às constatações e teorias dos pragmáticos cientistas empíricos. A partir do final do século XIX, a psicologia mudou de uma atividade filosófica introspectiva para uma prática empírica desenvolvida em laboratório.

Muitos temas clássicos em psicologia permanecem nas conversas filosóficas, ao menos por ora - a natureza da consciência, por exemplo -, mas vários outros foram suplantados pela investigação empírica. E, mais importante, várias das antigas questóes foram reformuladas, por vezes de forma bastante drástica, sob uma nova linguagem, extraindo seu significado a partir de um novo paradigma, como Kuhn ensinou o mundo a perceber. Portanto, a questão da "arte" desloca-se da procura por princípios inalteráveis pelos quais a "arte" pode ser reconhecida para a investigação dos modos como o termo é empregado nas atividades em curso de um mundo da arte. A ética transforma-se na investigação sociológica sobre como os julgamentos morais são produzidos e aplicados. Isso não significa que as velhas questões sobre moralidade, ética e conhecimento desapareceram. Tanto que estetas, epistemólogos e eticistas continuam a debatê-las, mas muito de seu território vem sendo colonizado por cientistas sociais, que estudam o mesmo terreno a partir de um ponto de vista diferente.

Posto que recorri à investigação empírica como o critério com o qual distinguimos o que acreditar e o que rejeitar, é importante realizar um pequeno percurso paralelo e tornar clara minha posição sobre o polêmico problema do relativismo, que subjaz a todos os três exemplos. Existem coisas "reais" de fato, às quais podemos recorrer para resolver nossas discordâncias? Ou se trata apenas da questão de quem pode gritar mais alto e encontrar mais aliados? Podemos encontrar o que é a verdade apelando para a realidade? Isso é o que, de fato, Selznick, o decano e os cientistas, em cujas bocas coloquei perguntas sobre aviōes e astrologia, estavam fazendo. Esta é a maneira como penso, e acredito que seja como a maior parte dos sociólogos; na verdade, a maioria dos cientistas empíricos profissionais também pensa quando estes não estão envolvidos em polêmicas que visam a garantir territórios e afins.

Algo é "real" - e, por conseguinte, deve ser levado a sério como critério que nos diz se o que pensamos ser verdadeiro deveria ser aceito como tal ou não -, quando o que digo sobre este algo for capaz de suportar todas as críticas e perguntas que as pessoas podem fazer para desacreditá-lo. Esta sempre foi minha convicção sobre como um sociólogo deveria trabalhar. Você antecipa o que os críticos sérios diriam - aquelas pessoas que realmente não desejam a sua conclusão sobre o que quer que seja ou que têm interesse em mostrar de todas as formas possíveis que você está errado. Então, você faz o que é necessário para combater as críticas, até que os críticos não mais consigam sustentá-las, pois você as respondeu tão bem que eles terão de aceitar seus argumentos. Isto não é exatamente a mesma coisa que gritar mais alto ou ter maiores habilidades políticas, mas se reporta ao acordo entre você e os críticos, segundo o qual eles não vão fazer mais nenhuma reclamação porque, em seus próprios pontos de vista, não há mais sustentação.

Essa posição tem dois antecedentes ou predecessores na literatura metodológica da ciência social. ${ }^{4} \mathrm{O}$ primeiro é a ideia de Donald Campbell de que o trabalho dos cientistas estabelece a verdade do que eles dizem por negociação, mediante "desafios de validação" de suas hipóteses, o que traduzi como "combater os argumentos que as pessoas poderiam dizer para obstruir o caminho da aceitação de uma hipótese”. Ele trouxe essa discussão a partir do contexto de um projeto experimental e quase experimental, delineando (com seus colaboradores Stanley e Cook) todas as possíveis objeções a vários tipos de projeto em psicologia social e às maneiras como se podem combatê-las. Ele acompanhou essas análises com a significativa ressalva de que você certamente jamais poderia, em uma pesquisa com seres humanos, lidar com todas as críticas possíveis, e, assim, você tem de escolher aquelas propensas a ocorrer e não se preocupar com as demais. Essa 
análise pode ser aplicada de forma bem-sucedida a todos os tipos de trabalho que os cientistas sociais realizam - pesquisas de campo, estudos históricos, pesquisas com questionários e assim por diante.

O segundo antecedente da minha posição é encontrado na discussão de Bruno Latour sobre como os cientistas validam suas constataçôes perante os colegas: uns submetem as constatações potenciais a vários tipos de "provas de força", às quais devem resistir; outros aceitam uma constatação que resistiu a todos os testes que puderam ser exercidos sobre ela e que sofreu a pior oposição passível de ser dirigida e, ainda assim, saiu vitoriosa. Cientistas que querem que seus colegas aceitem seus resultados como verdadeiros realizam um segundo procedimento: controlam os movimentos potenciais dos críticos, eliminando caminhos promissores de críticas e oferecendo respostas convincentes antes que os críticos comecem por este mesmo caminho. ${ }^{5}$ Em outras palavras, aceita-se como verdade, e não apenas como a opinião de alguém, uma declaração que ninguém criticou de forma incontestável, uma constatação que resistiu a todos os testes de força a que foi submetida por amigos e inimigos. Isto difere da prática popperiana, segundo a qual cientistas devem sempre tentar refutar alguma coisa. Ao contrário de Popper, não estou propondo um critério para que o que a verdade "realmente" é. Simplesmente digo o que, na prática, deve ocorrer para que outras pessoas que trabalham em seu campo aceitem o que você diz como verdade, ou uma verdade razoável.

Isso acrescenta outra dimensão para análise, pois o que proponho envolve uma maneira diferente de ver a questão da verdade. Para mim, essa questão não é um problema eterno de epistemologia, mas, sim, é aquela que surge para as pessoas em uma definição multipessoal - geralmente multiorganizacional -, onde o que é verdade se torna uma questão prática para cientistas profissionais lidarem. Em última instância, não pergunto se eles lidam com isso "corretamente", mas se lidam satisfatoriamente bem para calar os críticos. A análise consiste em olhar para a situação e perguntar quem critica quem e com quais resultados.

Então, direi que algo é verdade quando ninguém me fizer uma pergunta crítica capciosa a que eu não puder responder satisfatoriamente, forçan- do os críticos a balançarem a cabeça e efetivamente dizerem: "Bem, odeio admitir isso, mas acho que você está certo". Se todos ou a maioria dos membros da comunidade científica fazem tal reconhecimento, está suficientemente bom para mim considerar o resultado como verdade. Há um aspecto complicado aí, pois é claro que eu não iria tratar todas as questôes de todas as pessoas como dignas desse tipo de resposta séria. Quais questôes são aceitas na comunidade para a qual a ideia proposta se dirige? Para mim, neste momento, é a comunidade de cientistas sociais profissionais; e talvez nem todos eles porque, afinal de contas, não se trata de química, em que você tem de imaginar que todos os membros da comunidade compartilham padrões de prova indiscutíveis. Lembrem que as observações de campos realizadas por Kuhn mostraram que cientistas sociais passam muito mais tempo discutindo sobre estas dificuldades epistemológicas do que os cientistas da natureza. ${ }^{6}$

Respostas semelhantes para a acusação de relativismo podem ser feitas com relação a questões de arte e aos problemas de ética. É importante notar que o acordo sobre os resultados nesses campos não é tão necessário para a continuação do trabalho como no caso da ciência. Eticistas e estetas podem trabalhar muito tranquilos, apesar de discordarem sobre princípios fundamentais. Eles discordaram há pelo menos dois mil anos, e provavelmente continuarão a fazê-lo, mas os campos não sofrem com isso.

Podemos dizer que os objetos de arte existem independentemente de qualquer observador, mas o sentido em que isso é verdadeiro não é muito interessante para um cientista social, e a declaração deve ser imediatamente qualificada. $\mathrm{Na}$ verdade, obras de arte mudam e são alteradas constantemente, e a separação da "obra" em relação à discussão a seu respeito é difícil e só pode ser feita pelo acordo entre os participantes mediante alguma convenção que diga quando a obra é a obra da qual se fará a discussão. Uma vez que este tipo de acordo é alcançado, ainda que provisória e temporariamente, o debate sobre a "obra", então isolada, poderá correr satisfatoriamente. ${ }^{7}$

A avaliação do valor artístico passa continuamente pelas comunidades e redes de artistas profissionais. Uma vez que os artistas nunca concor- 
dam em todas as questóes, o acordo sobre o valor realmente funciona melhor em subcomunidades menores, embora, mesmo assim, as divergências como, por exemplo, se a música barroca deveria ser executada com instrumentos contemporâneos ou instrumentos do período em que foi escrita - produzam diferenças insolúveis. Discordâncias sobre o valor, porém, não impedem os artistas profissionais de aceitarem cooperar em questóes mais práticas, como a criação de espaços para a execução musical, ou sobre as obras que serão aceitas, para fins práticos, como parte de um acordo sobre o conjunto de "obras aceitáveis", boas o suficiente para serem exibidas ou executadas. Mas esta possibilidade muitas vezes não é realizada, e subcomunidades que aceitam diferentes padrōes existem lado a lado. Os membros dessas comunidades geralmente não têm problemas em experimentar as obras da mesma forma e chegar a juízos semelhantes. Então, direi que, contanto que eu aceite as premissas e compartilhe as experiências estéticas, posso concordar que uma obra de arte realmente é maravilhosa e que Mozart certamente é um gênio.

O mesmo ocorre com os problemas de ordem ética. Por estarem enraizados em formas da vida coletiva, como várias investigações sociológicas mostraram (especialmente sobre os chamados "problemas sociais"), tais problemas invariavelmente conduzem a um conflito e à incapacidade de se resolver as questôes de forma definitiva quando as premissas do modo de vida não são compartilhadas entre todos os participantes. Uma vez que tais premissas são compartilhadas, é possível para a pesquisa em ciência social investigar as alegações do fato, as relaçōes causais e os padrōes de influência que moldam a aplicação das normas de ética em questão. Então, direi que, na medida em que compartilho a forma de vida coletiva na qual os padrōes estão enraizados, inevitavelmente partilharei os juízos éticos seguidos.

A comparação entre a investigação empírica e a discussão filosófica - para retornar ao percurso principal - deixa claro que um aspecto fundamental desta última é de definibilidade, porém com uma distorção. Os empreendimentos que tenho caracterizado como filosóficos pretendem encontrar as regras que deveriam governar as definiçōes de valor. Os termos de definição são honoríficos: a "arte" é boa; a não arte não é; a "ciência real" é boa; a ciência "ruim" ou a "pseudociência" não é; "em conformidade com a lei" é bom; "criminoso" não é. A aplicação desses termos tem efeitos reais: se você vai para a prisão ou para casa, se as pessoas acreditam em suas descobertas ou as ironizam, se o que você fez é arte ou lixo. Quando as pessoas discutem sobre tais definições, está em jogo mais que apenas a precisão lógica.

A investigação filosófica da ética pode ser vista como um precursor primitivo do estudo sociológico do desvio, para ser deliberadamente provocativo. A maneira como as pessoas devem se comportar e julgar suas próprias condutas e as dos outros tem sido cada vez mais reformulada por sociólogos no âmbito do estudo de como as pessoas acham que os outros (e elas mesmas) deveriam se comportar. $\mathrm{E}$, ainda mais importante, no âmbito do estudo das organizações estabelecidas para criar e cumprir esses julgamentos e as consequências dessa atividade organizacional. Os filósofos ainda escrevem sobre problemas éticos e procuram por argumentos defensáveis para um ou outro sistema ético. Mas grande parte desse terreno está agora ocupado por sociólogos debatendo problemas relacionados, embora formulados de maneira diferente e destinados a serem respondidos de forma distinta, e as respostas são julgadas por sua adequação empírica. Não "como se deve comportar", mas "quem pensa o que sobre como alguém deveria se comportar e o que fazem a este respeito".

Da mesma forma, a estética sempre foi um campo de investigação filosófica, ainda que suas primeiras versões tivessem um caráter empírico. Mas as grandes questôes da estética quase sempre têm sido "o que é arte" e "qual é a grande arte", e o inverso, o que absolutamente não é arte. Trata-se de um esforço caracteristicamente negativo, projetado para evitar que o material indigno - que tem seus próprios nomes (pejorativos) como kitsch ou "cultura de massa" - seja confundido com a coisa real. A sociologia da arte, nas versōes que prefiro, evita essa pergunta e, em vez disso, analisa a forma como o termo "arte" é utilizado na vida organizacional dos mundos da arte. "Quem atribui este título?", "Como estas atribuições são mantidas e 
influenciam?”, "Com quais resultados?” - essas são as perguntas padrão em tal investigação empírica.

A epistemologia nos diz o que devemos julgar como "conhecimento real" e o que, sendo falso, não é digno de respeito. A sociologia da ciência não nos diz quão "real" o conhecimento é, mas, sim, que tipos de atividades organizadas produzem os resultados que os cientistas valorizam como científicos. Um bom exemplo é a investigação feita por Latour sobre o modo como cientistas franceses que estudam os solos realizaram a passagem, em seu estudo sobre os limites cerrado-floresta no Brasil, de fatos observados, como um trecho não marcado de floresta, para ideias abstratas, como a sucessão de um tipo ecológico para outro. Este problema epistemológico clássico é difícil de solucionar se você colocá-lo desta maneira: como você começa a partir de A e caminha até aqui, o ponto B, inimaginavelmente longe de onde começou? Latour mostra que os cientistas profissionais fazem a passagem com passos muito pequenos - da marcação de um pedaço de terra, para uma amostra escavada do solo, para uma caixa cheia dessas amostras, para um gráfico baseado nesta caixa e, por fim, para um artigo em periódico científico. Cada passo faz sentido para a comunidade, os resultados são apresentados e o mistério epistemológico é resolvido.

Não quero, ao fazer estas breves caracterizações, ser injusto com o campo da filosofia. A filosofia é um empreendimento mais variado do que a maioria das disciplinas acadêmicas e nenhuma afirmação resumida, como a que acabei de fazer, fará justiça a essa variedade. Enquanto vários filósofos se ocupam principalmente da análise normativa do tipo que eu critiquei, outros fazem o que a maioria dos cientistas sociais reconheceria como uma análise perfeitamente respeitável de ciências sociais. Aprendi, por exemplo, a ver a Poética de Aristóteles como um tratado empírico sobre as características das tragédias, que produziam efeitos específicos sobre os espectadores, um tipo de psicologia social ou, talvez até, como diríamos hoje em dia, um estudo da recepção das obras dramáticas. Porém, em subcampos filosóficos como a ética, a estética e a epistemologia, o objetivo principal não é empírico, mas analítico e normativo.

Mesmo quando os filósofos discutem a organi- zação social, eles o fazem de maneira hipotética, inventando exemplos para ilustrar as categorias que desenvolveram em suas análises. Assim, filósofos como Arthur Danto e George Dickie, quando traçam juízos de valor estético para as operaçôes de uma entidade que eles chamam "mundo da arte", não discutem nenhum mundo da arte em particular em sua completa realidade organizacional. Em vez disso, eles usam coisas que aconteceram ou poderiam acontecer em algum campo da arte para trazer à tona as distinçôes que estão fazendo. Assim, Dickie se dedicou a questôes como esta: suponha que o tratador de um elefante do zoológico tenha proposto este animal como um candidato a obra de arte. Isso faz do elefante arte? Bem, trata-se de uma pergunta, mas não daquelas que, de alguma forma, são debatidas contemporaneamente nos mundos da pintura, da escultura, da literatura, do teatro, entre outros.

Quando as operações do mundo da arte começam a aparecer nas discussões dos estetas, não é o mesmo mundo da arte observado pela socióloga Raymonde Moulin, no qual juízos de valor estético dos participantes estão inextricavelmente misturados aos juízos de valor financeiro. Não porque as pessoas envolvidas sejam mercenárias, mas porque a organização do mundo da arte da pintura contemporânea torna isso inevitável. Nem era o mundo das barganhas, das negociações e dos mercados bastante incertos analisados pelo economista Richard Caves. Ou o mundo da Grande Hollywood descrito por Robert Faulkner, em que uns poucos artistas das principais categorias profissionais fazem, entre si, metade dos filmes que Hollywood distribui cada ano.

Estetas perseguem a lógica de como tais mundos atingem os julgamentos coletivos a que eventualmente chegam, mas não a realidade organizacional confusa dos curadores, dos negociantes, dos colecionadores e dos críticos, e seus múltiplos e conflituosos motivos, que os cientistas sociais descrevem. $\mathrm{O}$ mundo da arte é, para eles, um dispositivo lógico que ajuda a explicar como um sistema de julgamentos estéticos pode funcionar.

O mesmo é verdade - aí está outra ampla generalização com várias exceções - para a epistemologia, que procura por critérios que venham a distinguir a 
ciência real das bobagens. Latour, abordando questôes epistemológicas, não procura uma justificativa lógica para um resultado, mas, sim, o modo como aquela interrogação é transformada, no trabalho dos cientistas, em uma série de pequenos e incontroversos passos que conduzem a um resultado aceitável pela comunidade de cientistas a que é dirigido. Não há uma lógica da verdade definitiva em tal análise, apenas uma compreensão da lógica utilizada pelas pessoas que fazem a ciência que todos nós aceitamos.

Muito frequentemente estas duas formas de fazer as coisas - a estética e a sociologia da arte, a ética e os estudos de desvio, a epistemologia e a sociologia da ciência - só existem lado a lado. Cada uma cuida do seu próprio negócio, fala para seu próprio público disciplinar. Mas, às vezes, elas entram em conflito uma com a outra e, outras vezes, criam conflitos no interior de uma das disciplinas de origem.

\section{Conflito intergrupal}

Isto é o que aconteceu entre mim e o decano em relação a Mozart. Ele era um esteta e podia ver que eu estava cometendo uma heresia sugerindo que arte e gênio, e todos os conceitos relacionados tão centrais a uma abordagem da estética, fossem convenções sociais. ${ }^{8}$ Segundo ele, eu deveria admitir que aquilo em que as pessoas como ele estavam interessadas - arte e gênio e tudo mais - eram reais, não apenas o resultado de algum acordo entre as partes interessadas. Acordos podem ser modificados, e isso significaria que aquelas obras sagradas não eram, de maneira muito significativa, "reais". Para um sociólogo, nada é mais real do que o acordado pelas pessoas, ao qual conferimos centralidade por meio das "definições da situação".

Por que um esteta deveria se preocupar com o pensamento dos sociólogos? Acho que ele queria um reconhecimento da realidade dos seus conceitos. Ele queria que eu - e, por extensão, os cientistas sociais em geral - admitisse que algumas características dos objetos artísticos não são relativas, que não se trata de uma questão de opinião e consenso, mas, sim, qualidades inerentes daqueles objetos, e que estas características inerentes haviam sido verificadas como tais pela ciência social.

Se os cientistas sociais concordarem com isso, então a agenda de pesquisa deles teria de mudar. Nós deveríamos nos dedicar a responder questóes tais como "sob quais condições a grande arte é criada?", considerando o adjetivo "grande", como geralmente é aplicado, enquanto um dado da pesquisa. Não estaríamos muito interessados na reputação flutuante das obras, uma das bases do relativismo da ciência social diante das artes. Que Shakespeare tenha sido alguma vez considerado menor do que atualmente é não seria algo de verdadeiro interesse e poderia ser descrito como cegueira, preconceito e ignorância das gerações anteriores.

Nesses casos, o local para o qual o decano e pessoas como ele apelam é o senso comum dos amantes de arte informados e dos críticos; senso comum este que meu pai, fiel devoto dessas ideias, chamou de "a sabedoria dos antigos". Minha insistência de que as reputações flutuam, de que as características de um trabalho surgem da interação entre um objeto em constante mudança e uma variedade de apreciadores em rotatividade permanente, parece um desconhecimento voluntário - perverso e provocativo - de toda sabedoria e conhecimento. $\mathrm{O}$ mesmo ocorre nas querelas sobre o significado de conceitos moralmente carregados, como crime e desvio, e nas ideias de ciência. No estudo do desvio, os grupos profissionais que possuem o território - polícia, advogados, políticos, psiquiatras e outros médicos - criam os entendimentos do senso comum que uma investigação sociológica torna seu objeto de estudo. Quando o meu colega me perguntou "E o assassinato?", ele estava expressando a compreensão do senso comum de que o assassinato é realmente diferente e requer uma explicação distinta das ações "menos graves" que podem ser, em termos de definição, menos claras. Ele queria que eu reconhecesse essa diferença e concordasse que tal caracterização estava cientificamente fundamentada.

No que diz respeito à ciência, os cientistas (muitos dos quais acadêmicos) não conseguem entender por que colegas investigadores da realidade se recusam a reconhecer a qualidade superior do conhecimento que eles produzem, e ficam particularmente furiosos pelo que eles (incorretamente) tomam por uma implicação da sociologia da ciência: sendo a ciência apenas uma questão de acordo 
entre pessoas, logo eles poderiam aceitar tudo, e isso transformaria qualquer coisa em ciência. Eles querem que nós, os sociólogos, concordemos que a nossa própria ciência, a sociologia, ratifique as afirmações feitas pelas outras ciências.

\section{Conflito intragrupal}

Falei como se essas atitudes e abordagens fossem distribuídas simplesmente ao longo de linhas disciplinares, mas, é claro, isso não acontece. A arte e as disciplinas humanísticas estão repletas de pessoas tão relativistas quanto a construção social mais dedicada poderia pedir. Isso é muito comum pelo bom motivo de que elas estão pessoalmente familiarizadas com os altos e os baixos da reputação - é o que elas estudam - e sabem o quanto as reputações mudam com facilidade e em que bases frágeis as mudanças repousam. Sua própria leitura das evidências os conduziu a uma conclusão sociológica. Você poderia dizer que são sociólogos sem saber. Encontrei inspiração e métodos úteis e resultados no trabalho de pessoas como Barbara Hernnstein Smith, Michael Baxandall, Scott Deveaux, Paul Berliner e outros de campos de conhecimento diversos.

Por outro lado, alguns sociólogos aceitam que existem características inerentes a eventos, objetos e atividades, que sobrevivem a todas as variações de contextos sociais e só podem ser interpretados e compreendidos como portadores destas características imutáveis. Eles concordam que algumas obras de arte são trabalho de gênios, que algumas formas de ciência são autênticas, enquanto outras atividades são falsa ciência, e algumas atividades são realmente desviantes.

Não me recordo de tudo o que disse a Philip Selznick na ocasião que descrevi anteriormente, mas isso é o que eu diria agora e disse em situações similares desde então. Eu o fiz lembrar que as pessoas não concordam sobre quais atos constituem um assassinato; que um assassinato, sob um conjunto de circunstâncias, é um homicídio justificável e, sob outras, não; que, em vários momentos e lugares, o assassinato ou algo que seria difícil de explicar a partir disso foi, de fato, a única maneira disponível de resolução de disputas; e assim por diante. Isso não o satisfez e não vai satisfazer ninguém que acredita que um assassinato seja inerentemente desviante.

Nem esses equívocos satisfazem as pessoas que, em circunstâncias anteriores, me perguntaram por que eu não estava disposto a dizer que o capitalismo ou o patriarcado ou a homofobia eram "realmente desviantes", como muitas pessoas estavam prontas para afirmá-lo.

Por fim, gostaria de ter dito, já que compartilho várias dessas opiniōes, que estava perfeitamente preparado para dizer que todas aquelas coisas eram más, nojentas ou quase qualquer outra palavra desagradável que quisessem usar. E eu teria perguntado por que isso não foi suficiente. Porque não teria sido. Nem teria sido suficiente para mim dizer ao decano que, sendo eu mesmo músico, senti-me como ele se sentiu a respeito de Mozart. E me senti da mesma maneira a respeito de Dizzy Gillespie e Stan Getz e um monte de outros músicos de jazz (porque fui e sou músico de jazz), opiniōes que duvido que ele compartilharia. Assim como meu acordo (porque, apesar de tudo, sou um profissional da ciência também) com todos aqueles que pensam que astrologia não é ciência não satisfaria os críticos, porque eles não teriam aceitado meu adendo, enquanto outros compartilham minha definição local do que constituiria a ciência.

Por que essas respostas não seriam aceitáveis? $\mathrm{O}$ que estou prestes a dizer possui uma influência bastante geral em vários problemas da ciência social. Essas respostas não iriam funcionar, porque o que essas pessoas pedem não é apenas um acordo com seus julgamentos, o que frequentemente tenho prazer em fazer, mas uma declaração de que isso não é uma questão de opinião pessoal, mas uma constatação científica, um resultado que carrega a garantia de um conhecimento certificado. Não que o decano e eu concordemos que Mozart é incrível, mas que haja uma objetividade, uma evidência irrefutável de que ele é. Não que nós concordemos que o assassinato é terrível, mas que a terribilidade é um resultado científico, não uma emoção compartilhada.

Por que alguém insistiria nisso? Porque a ciência e o conhecimento certificado que se acredita que ela produza são a única base sobre a qual qualquer um pode sempre ganhar uma discussão. Se eu digo que minha opinião sobre alguma destas questôes é 
correta porque, vamos dizer, a verdade religiosa de que você não deve assassinar me foi revelada pelas escrituras sagradas, vários dos meus leitores que não aceitam a revelação religiosa como fonte de conhecimento não aceitarão minha conclusão. E não tenho nada mais convincente para dizer a eles. Se eu digo que meus instintos me falam que Stan Getz é um saxofonista melhor que Kenny G jamais será, isso convencerá apenas as pessoas que já concordam comigo. Essas e outras sutilezas semelhantes não proporcionam a certeza e o poder de persuasão que apenas a ciência pode providenciar.

Por que não aceito tais juízos, os quais realmente aceito na minha vida como cidadão, pianista e profissional da ciência social? Porque, se o fizesse, estaria me comprometendo com um programa de pesquisa fadado ao fracasso. Um passo importante na pesquisa é estabelecer classes de fenômenos sobre os quais generalizar. ' Se os membros da classe não são os mesmos de uma forma relevante para o que você queira generalizar, você não vai encontrar nenhuma generalização interessante. Isso é o que você faz quando cria uma classe definida por como outras pessoas (juízes, policiais, psiquiatras) têm reagido. É o que você faz quando considera a condenação por crime como algo sobre a natureza íntima do condenado, em vez de algo sobre o processo de condenação. As pessoas condenadas podem ter outras coisas em comum além de estarem condenadas, mas isso não é garantido. $\mathrm{Ou}$, melhor, é garantido apenas se a infalibilidade do processo destaca pessoas que têm algo a mais em comum, tais como ter cometido certo ato, o que não é algo com que alguém possa contar.

Quando Donald Cressey, desejando estudar estelionatários, pensou que podia encontrá-los selecionando uma amostra de pessoas condenadas por este crime, logo percebeu que não conseguiria reunir um grupo de pessoas em que todas tivessem feito a mesma coisa da mesma maneira. Isso porque os promotores não acusam pelo que as pessoas fizeram de fato, mas pelo crime pelo qual se pode condená-las. As definiçõos dos crimes financeiros geralmente tornam impossível processá-las por estelionato, o crime que Cressey desejava estudar. Ele teve de criar outras definiçôes e, então, encontrar pessoas entre os prisioneiros disponíveis que se encaixavam na definição do tema que ele desenvol- veu: "a violação criminal da confiança financeira".

Este é o problema clássico da boa pesquisa em ciência social. Não podemos criar classes homogêneas de atividade pelas quais seremos capazes de encontrar processos causais adequados se dependermos das definiçōes disponíveis nos mundos que estudamos. Estas definiçōes são feitas, como Garfinkel demonstrou há tempos, para propósitos diferentes da ciência social e refletem uma série de compromissos organizacionais engendrados e recursos que só podem impedir nossos esforços em produzir alguma ciência social.

Mas, quando ignorarmos o "senso comum", a "sabedoria convencional" ou "a sabedoria dos antigos", seguramente marcharemos em oposição às pessoas que assumem aquelas definições como autoevidentes. Este é o nosso dilema e não há solução fácil.

\section{Notas}

1 Este ensaio aborda alguns dos temas do livro de $\mathrm{Na}$ talie Heinich, Ce que l'art fait à la sociologie, Paris, Minuit, 1998. Acredito que a autora chega a uma posição semelhante, seguindo um caminho de análise mais filosófico.

2 "Desviante" foi um termo geral que alguns de nós começamos a utilizar para englobar toda sorte de categorias negativas que surgiram em áreas específicas: "criminoso", "louco", "anormal”, "pervertido", "antiético" etc.

3 No que se segue, não tenho a intenção de, para usar uma citação de Heinich, "destronar” a filosofia, mas apenas de notar o que vem acontecendo nos campos do trabalho filosófico.

4 Estou certo de que existem outros, mas estes foram os que me influenciaram.

5 Latour chama isso de "captação", adotando um termo retórico para este propósito.

6 Para essa discussão, aproveitei as observações de Ian Hacking.

7 Obviamente, as mudanças que ocorrerem no trabalho vão criar anomalias que produzirão problemas para os participantes.

8 Em uma manobra favorita do discurso filosófico, ele poderia ter me acusado de dizer que eram "meras" convenções sociais.

9 Não se deve necessariamente fazer isso no início, mas se deve fazer em algum momento. 


\section{E MOZART? E O ASSASSINATO?}

Howard S. Becker

Palavras-chave: Desvio; Sociologia da arte; Sociologia da ciência; Rotulação; Definição da situação.

Escrito de forma despojada e bem humorada, este artigo serve como introdução ao pensamento desenvolvido pelo sociólogo norte-americano Howard Becker. Seu ponto de partida foi observar as implicaçôes da adoção do conceito de "definição da situação" em três campos distintos da atividade sociológica: a sociologia do desvio, a sociologia da arte e a sociologia da ciência. Ao compartilhar suas experiências como pesquisador, Becker pretende se desvencilhar de perspectivas teóricas imanentes com o objetivo de reforçar, por meio de seu conceito de "rotulação", a centralidade da significação como instância articuladora das práticas sociais. Ademais, esta tradução é particularmente importante para público brasileiro, pois apresenta a visão de Becker sobre a sociologia do trabalho artístico, uma vez que Art worlds, sua obra de referência acerca dessa temática, ainda não foi editada em nosso país.

\section{WHAT ABOUT MOZART?} WHAT ABOUT MURDER?

\author{
Howard S. Becker
}

Keywords: Deviance; Sociological research; Sociological knowledge and case studies; Labeling; Definition of the situation; Meaning and social practices.

Written in a simple and humorous way, this article serves as an introduction to the thought of the American sociologist Howard S. Becker. In this sense, his starting point is to observe the implications of adopting the concept of "definition of the situation" in three distinct fields of sociological activity: the sociology of deviance, the sociology of art, and the sociology of science. By sharing his experiences as a researcher, Becker intends to disentangle himself from immanent theoretical perspectives with the goal of enhancing, through the concept of "labeling", the centrality of meaning as an articulatory instance of social practices. The present translation is particularly important for the Brazilian public because it presents Becker's vision about the sociology of the artistic work, since his reference book on the topic - Art Worlds - has not yet been published in our country.

\section{ET MOZART? ET LE MEURTRE?}

\author{
Howard S. Becker
}

Mots-clés: Déviation; Sociologie de l'art; Sociologie de la science; Étiquetage.

Rédigé de façon simple et avec beaucoup d'humour, cet article sert d'introduction à la pensée du sociologue américain Howard Becker. Son point de départ consiste à observer les implications de l'adoption du concept de "définition de la situation" dans trois différents domaines de l'activité sociologique : la sociologie de la déviation, la sociologie de l'art et la sociologie de la science. En partageant ses expériences en tant que chercheur, Becker prétend se débarrasser de perspectives théoriques immanentes, dans le but de renforcer, à travers le concept d'étiquetage", la centralité de la signification comme instance d'articulation des pratiques sociales. En outre, cette traduction est particulièrement importante pour le public brésilien, puisqu'elle présente la vision de Becker sur la sociologie des travaux artistiques, étant donné que son œuvre Arts works, principale référence sur cette thématique, n’a pas été publiée au Brésil. 